\title{
Reversible White Matter Lesions in a Patient with Fulminant Hepatitis and Acute Renal Failure
}

\author{
Masayuki Ikeda, Kazuo Takahashi*, Takashi Matsunaga and Hiroshi Tsukagoshi**
}

\begin{abstract}
A 36-year-old man developed fulminant hepatitis and acute renal failure with profound hyponatremia $(116 \mathrm{mEq} / \mathrm{L})$. Emergent hemodialysis corrected the serum sodium to $136 \mathrm{mEq} / \mathrm{L}$ within 24 hours. He developed generalized convulsions 11 days later. Magnetic resonance imaging (MRI) revealed a single large symmetrical lesion in the pons and extensive white matter lesions in the bilateral occipital, temporal, parietal and right frontal regions. These lesions showed marked resolution as the patient recovered. Fulminant hepatitis and acute renal failure could induce extensive edema in the cerebral white matter. Therefore, not all MRI abnormalities in the white matter after correction of hyponatremia necessarily reflect myelinolysis.
\end{abstract}

(Internal Medicine 33: 360-362, 1994)

Key words: central pontine myelinolysis, magnetic resonance imaging, brain edema, hyponatremia, hepatorenal syndrome

\section{Introduction}

Central pontine and extrapontine myelinolysis (CPM/EPM) is an osmotic demyelination syndrome that occurs after rapid correction of hyponatremia (1). As CPM/EPM has become a more widely recognized entity owing to magnetic resonance imaging (MRI), some questions have arisen: e.g. factors that discriminate between cases with CPM only and those with both CPM and EPM (2-4); the correlation between the pathology and the radiologic imaging of the lesions $(5,6)$. To address these questions we describe a CPM patient with large extrapontine lesions caused by fulminant hepatitis and acute renal failure.

\section{Case Report}

A 36-year-old Japanese man was admitted because of fulminant hepatitis and acute renal failure. He had traveled to Taiwan and had had sexual intercourse there six weeks before admission. Four weeks later, fever, anorexia and general malaise developed and were exacerbated. There was no history of alcohol abuse. On the day of admission he was found to be confused and was brought to our hospital.

On physical examination, the body temperature was $35.4^{\circ} \mathrm{C}$. Blood pressure was $168 / 70 \mathrm{~mm} / \mathrm{Hg}$ and the pulse $72 / \mathrm{min}$. Skin and eyes were icteric. His breath had the odor of ammonia. The neck and chest were unremarkable. The abdomen was soft and flat. The liver and the spleen were not palpable. There was no pitting edema in the legs. On neurological examination, he was arousable but could not follow simple commands. He withdrew his extremities promptly in response to noxious stimuli. The neck was supple. His pupils were equal in size and reacted to light promptly. The deep tendon reflexes were normal in the arms but hyperactive in the legs without Babinski's sign.

Laboratory tests disclosed the following values: serum sodium $116 \mathrm{mEq} / \mathrm{L}$, potassium $4.3 \mathrm{mEq} / \mathrm{L}$, chloride $79 \mathrm{mEq} / \mathrm{L}$, urea nitrogen $127 \mathrm{mg} / \mathrm{dl}$, creatinine $12.6 \mathrm{mg} / \mathrm{dl}$, glucose 104 $\mathrm{mg} / \mathrm{dl}$, serum aspartate aminotransferase 5,170 IU/L, total bilirubin $11.06 \mathrm{mg} / \mathrm{dl}, \mathrm{NH}_{3} 163 \mathrm{mg} / \mathrm{dl}$. Hepatitis B virus (HBV) surface antigen ( $\mathrm{HBsAg}$ ) and anti-hepatitis B core IgM antibody (anti-HBc IgM) were positive. Serological tests for syphilis and anti-human immunodeficiency virus antibodies were negative. An electroencephalogram was abnormal because of generalized, irregular slowing at $50-70 \mu \mathrm{V}$, without asymmetry. A computed tomographic (CT) scan of the head showed no abnormality on admission.

We performed emergent hemodialysis for the acute renal failure and plasmapheresis for the fulminant hepatitis. His serum sodium level rose to $136 \mathrm{mEq} / \mathrm{L}$ within 24 hours as a result of the hemodialysis. He gradually recovered and we stopped the plasmapheresis on day 4 . On day 10 he became more responsive and answered simple questions but on day 12 generalized convulsions developed. He became comatose. $\mathrm{He}$

\footnotetext{
From the Department of Neurology, *the Department of Medicine, Asahi General Hospital, Asahi, and **the Department of Neurology, School of Medicine, Tokyo Medical and Dental University, Tokyo

Received for publication November 16, 1993; Accepted for publication April 1, 1994

Reprint requests should be addressed to Dr. Masayuki Ikeda, the Department of Physiological Chemistry, Graduate School, Tokyo Medical and Dental University, Tokyo 113
} 
promptly withdrew all extremities in response to noxious stimuli but made no purposeful movements. His pupils were equal in size and reacted to light. There were transient roving eye movements. The deep tendon reflexes were hyperactive without Babinski's sign. MRI on the same day showed a single large symmetrical hyperintensity in the pons. Hyperintense signal abnormalities were also found in the cerebral white matter in the bilateral occipital, temporal, parietal and right frontal regions (Fig. 1a, b, c). The rapid correction of hyponatremia and the typical radiologic finding in the pons led to the diagnosis of CPM. Laboratory tests showed a recurrence of hepatic failure.

Dexamethasone and glycerol were administered and plasmapheresis was restarted. His condition and laboratory data gradually improved. Two months later on discharge, his consciousness was almost clear without any difficulty in verbal communication. However, he was alexic, agraphic and disoriented in time and place. His visual field appeared intact by the confrontation test. He had no facial weakness, dysphagia or dysarthria. He was mobile and had no motor weakness. Deep tendon reflexes were normal without Babinski's sign. MRI showed a marked resolution of the lesions. Some hyperintense T2 signals remained in the occipital region (Fig. 1d, e, f).

\section{Discussion}

This is a case of fulminant hepatitis associated with acute renal failure: hepatorenal syndrome (7). The positive HBsAg and anti-HBcIgM indicate that fulminant hepatitis was caused by HBV (8). It is supposed that the patient became infected with HBV through sexual intercourse in Taiwan where the carrier rate of HBsAg is very high (8). The period of six weeks between the exposure and the onset agrees with the usual incubation period of hepatitis B (8).

Although liver diseases are often associated with hyponatremia, its etiology is multifactorial (9). In the present case, fulminant hepatitis was one of the causes of hyponatremia, because patients with decompensated liver diseases have an
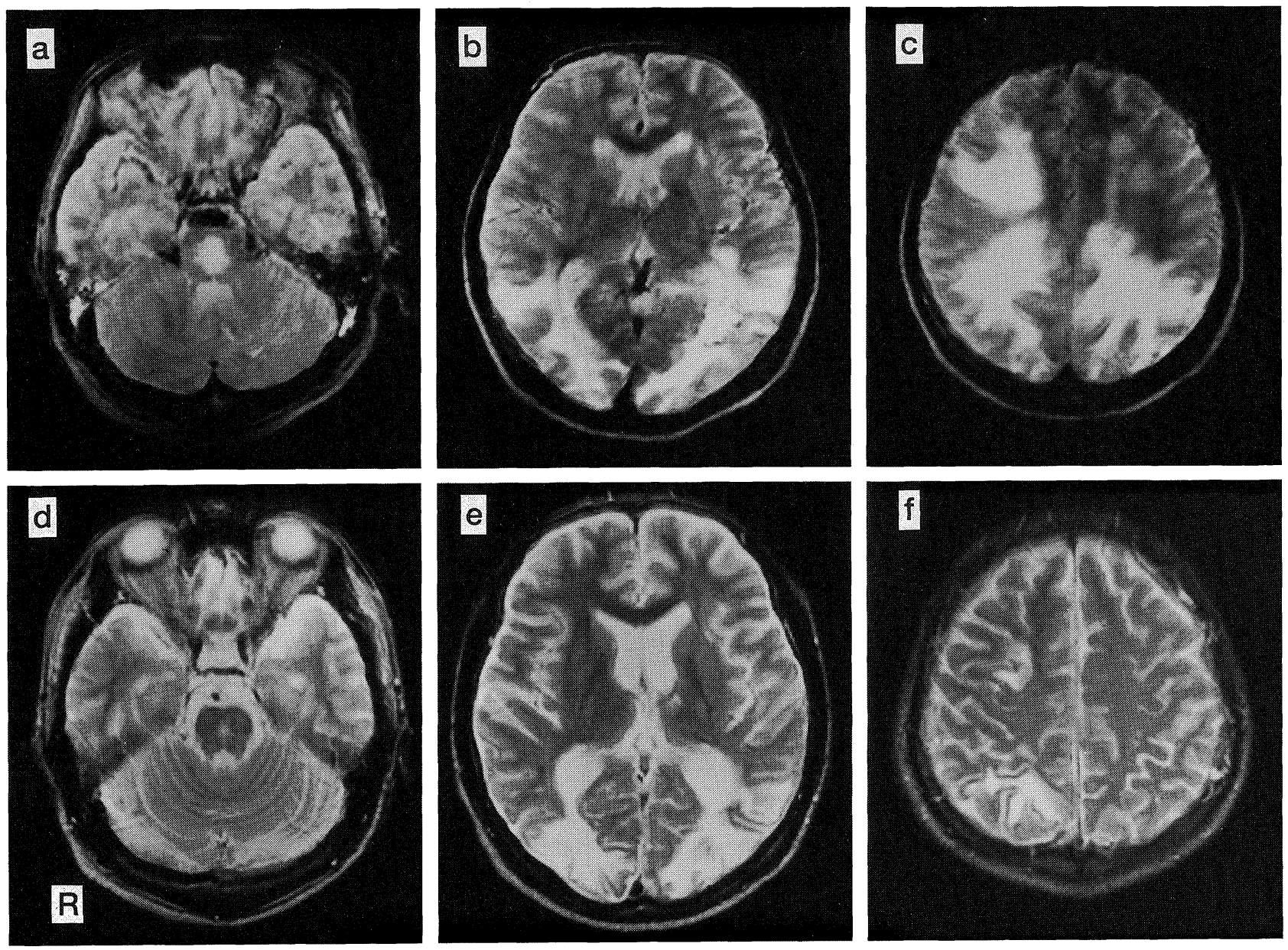

Fig. 1. Cranial magnetic resonance imaging (MRI). T2-weighted ( $\mathrm{TR}=2000 / \mathrm{TE}=30$ ) images at 1.5 tesla on day 12 (a, b, c), showing a single large symmetrical hyperintensity in the pons (a). Hyperintense signal abnormalities are found in the white matter in the bilateral occipital, temporal, parietal and right frontal regions $(b, c)$. MRI two months later on discharge shows a marked resolution of the lesions $(\mathrm{d}, \mathrm{e}, \mathrm{f})$. Considerable hyperintensities remain only in the bilateral occipital regions. 
increased body water volume (10). Acute renal failure also contributed to hyponatremia with deranged sodium handling and impaired water excretion (7).

The characteristic finding in the present case is the extensive cerebral white matter lesions. The radiologic features suggest that these lesions are largely edema rather than myelinolysis. CT shows low absorption areas exclusively affecting the subcortical white matter. This pattern is typical of brain edema. The marked resolution of the lesions on MRI also suggests that they are reversible (i.e. edema) rather than irreversible as is myelinolysis. Lesions are visualized on MRI largely due to an increase in the proton content in tissue water (11). Loss of myelin alone is unlikely to affect the MRI intensity because the lipid protons in myelin make only a negligible contribution to the normal brain signal (12). In fact, MRI can fail to detect pathologically confirmed demyelination caused by a rapid correction of hyponatremia (5). After the edema disappeared, hyperintense $\mathrm{T} 2$ signals remained in the occipital region. They may be gliosis instead of myelinolysis because the astrocytes, with their abundant cytoplasm, would result in an increase in tissue water content (6).

The extent and the site of the lesions are also atypical for EPM. There are many reports on EPM (2-4) but the lesions are usually small. EPM often affects the cerebellum, lateral geniculate body and basal ganglia $(3,4)$ but rarely extends to two or more cerebral lobes that are less vulnerable to myelinolysis than the base of the pons (13).

In the present case, fulminant hepatitis and acute renal failure may have induced brain edema. Hepatic failure disrupts the blood-brain barrier causing brain edema, which is the most common finding contributing to death in hepatic encephalopathy (14). In relation to acute renal failure, uremia can cause patchy cerebral white matter edema similar to the lesion in the present case (15). Hemodialysis also induces a brain-to-plasma osmotic gradient that results in brain edema (16). Dettori and coworkers observed changes in brain density on CT in dialyzed patients (17).

In conclusion, fulminant hepatitis and acute renal failure can impair the osmolarity balance of the blood-brain barrier to induce brain edema. Hyperintense T2 signals in the brain on MRI after a rapid correction of hyponatremia may be edema, not necessarily reflecting myelinolysis.

\section{References}

1) Sterns RH, Riggs JE, Schochet SS. Osmotic demyelination syndrome following correction of hyponatremia. N Engl J Med 314: 1535, 1986.

2) Endo Y, Oda M, Hara M. Central pontine myelinolysis. A study of 37 cases in 1000 consecutive autopsies. Acta Neuropathol 53: 145, 1981.

3) Gocht A, Colmant HJ. Central pontine and extrapontine myelinolysis: a report of 58 cases. Clin Neuropathol 6: 262, 1987.

4) Wright DG, Laureno R, Victor M. Pontine and extrapontine myelinolysis. Brain 102: 361, 1979.

5) Clifford DB, Gado MH, Levy BK. Osmotic demyelination syndrome. Arch Neurol 46: 343, 1989.

6) Thompson PD, Miller D, Gledhill RF, Rossor MN. Magnetic resonance imaging in central pontine myelinolysis. J Neurol Neurosurg Psychiatry 52: $675,1989$.

7) Epstein M. Hepatorenal syndrome. in: Gastroenterology, 4th ed, Berk JE, Haubrich WS, Kalser MH, Roth JLA, Schaffner F, Eds. WB Saunders, Philadelphia, 1985, p. 3138.

8) Sherlock S. Diseases of the liver and biliary system, 8th ed. Blackwell, Oxford, 1989, p. 301.

9) Arieff A, Papadakis MA. Hyponatremia and hypernatremia in liver disease. in: The Kidney in liver disease, 3rd ed, Epstein M, Ed. Williams \& Wilkins, Baltimore, 1988, p. 73.

10) Papper S. Fluid and electrolyte disturbances in cirrhosis. Am J Med Sci 272: 53, 1976.

11) Ormerod IEC, Miller DH, McDonald WI, et al. The role of NMR imaging in the assessment of multiple sclerosis and isolated neurological lesions. Brain 110: 1579, 1987.

12) Bottomley PA, Hart Jr HR, Edelstein WA, et al. Anatomy and metabolism of the normal human brain studied by magnetic resonance at 1.5 tesla. Radiology 150: 441, 1984.

13) Messert B, Orrison WW, Hawkins MJ, Quaglieri CE. Central pontine myelinolysis: consideration on etiology, diagnosis, and treatment. Neurology 29: 147, 1979.

14) Fraser CL, Arieff AI. Hepatic encephalopathy. N Engl J Med 313: 865, 1985.

15) Anlar B, Erzen C, Saatci U. Patchy cerebral white matter edema in chronic renal failure. Pediat Radiol 19: 444, 1989.

16) Arieff AI, Lazarowitz VC, Guisado R. Experimental dialysis disequilibrium syndrome: Prevention with glycerol. Kidney Int 14: 270, 1978.

17) Dettori P, LaGreca G, Biasioli S, et al. Changes of cerebral density in dialyzed patients. Neuroradiology 23: 95, 1982. 